\title{
Incidental appendix neuroendocrine tumor and current treatment approach in patients with acute appendicitis
}

\section{Akut apandisit ön tanısı ile opere edilen olgularda insidental apendiks nöroendokrin tümörü ve güncel tedavi yaklaşımı}

\author{
Gökhan Demiral, Muhammet Kadri Çolakoğlu, Süleyman Kalcan, Ali Özdemir, Ali Demir, Ahmet Pergel \\ Sağlık Bakanlığı Recep Tayyip Erdoğan Üniversitesi Eğitim Ve Araştırma Hastanesi, Rize
}

Dergiye Ulaşma Tarihi:10.10.2017 Dergiye Kabul Tarihi:23.11.2017 Doi: 10.5505/aot.2018.30092

\section{ÖZET}

Amaç: Apendiks, eskiden karsinoid tümör olarak adlandırılan nöroendokrin tümörlerin (NET) en sık görüldüğü yerlerden biridir. Çoğunlukla semptomsuz olup apendektomi veya diğer abdominal ameliyatlar sonrasında insidental olarak saptanır. Bu çalışmada akut apandisit ön tanısı ile apendektomi uygulanan hastaların patoloji sonuçları incelenerek NET saptanan hastalar değerlendirildi.

Yöntem: Ocak 2015 - Aralık 2016 tarihleri arasında hastanemizde akut apandisit ön tanısı ile opere edilen 586 hastanın dosyası ve apendektomi piyeslerine ait patoloji sonuçları retrospektif olarak incelendi. Hastaların yaş, cinsiyet ve histopatolojik tanıları ile apendiks NET olarak rapor edilen olguların makroskopik tümör bulgu durumu, tümör yeri, tümör boyutu, cerrahi sınır, Ki 67 indeksi, mitotik indeks ve sonraki tedavileri değerlendirildi. Bulgular: Hastaların 365' i erkek 228' i kadın olup, yaş ortalaması 28.2 (1- 88) idi. Üç hastada (\% 0.5) iyi diferansiye NET saptandı. Bu üç hastaya ait spesmenlerde akut apandisit tespit edilmedi. Hastaların yaşları 15, 35 ve 48 idi. Tümör boyutları 0.4, 0.6 ve $1.2 \mathrm{~cm}$ idi. Tüm olgularda tümör distal yerleşimli idi. Cerrahi sınır iki hastada negatif bir hastada pozitif idi. Her üç hastada Ki 67 proliferasyon indeksi \% 2' den az ve mitotik indeks $<2 / 10 \mathrm{Hpf}$ idi. Cerrahi sınır pozitif olan hastaya ameliyat sonrası 1. ay săg hemikolektomi yapıldı. Diğer iki hasta takip önerilerek taburcu edildi.

Tartışma ve sonuç: Apendiks NET' lere histopatoloji öncesinde tanı koymak oldukca zordur. Yaşam beklentisi iyi olmakla birlikte senkron veya metakron kolorektal malignite gelişme olasılığı unutulmamalıdır.

Anahtar Kelimeler: Apendiks nöroendokrin tümörü, apendektomi, insidental.

\begin{abstract}
Introduction: The appendix is one of the common sites of neuroendocrine tumor (NET) which was formerly called as carcinoid tumor. It is mostly asymptomatic and incidentally detected after appendectomy or other abdominal operations. In this study, pathology results of patients which underwent operation for acute appendicitis and diagnosed as NET were evaluated.

Methods: The files and pathology results of 586 patients which were operated for acute apandicitis in Recep Tayyip Erdoğan University Educational and Research Hospital between January 2015 and December 2016 were evaliuated retrospectively. The age, gender, histopathological diagnosis of the patients and the macroscopic tumor findings, tumor site, tumor size, surgical margin, Ki 67 index, mitotic index and subsequent treatments of the cases that was reported as appendicitis were evaluated.

Results: 365 of the patients were male and 228 female. The mean age was 28.2 (1-88). Well differentiated NET was detected in three patients $(0.5 \%)$. Acute appendicitis was not detected in the specimens of these three patients. The ages of the patients were 15, 35 and 48 years. Tumor sizes were $0.4,0.6$ and $1.2 \mathrm{~cm}$. In all cases, the tumor was on distal site. The surgical margin was negative in two patients and positive in one patient. Ki 67 proliferation index was $<2 \%$ and mitotic index $<2 / 10 \mathrm{Hpf}$ in all three patients. Right hemicolectomy was performed in the first month after surgery in the patient with positive surgical margin. Two other patients were offered follow-up and discharged.

Discussion and conclusion: It is difficult to diagnose appendix NET before histopathological examination. Life expectancy is well in these patients. However the possibility of development of synchronous or metachronous colorectal malignancies should not be forgotten.
\end{abstract}

Keywords: Appendix neuroendocrine tumor, appendectomy, incidental. 


\section{GİRIŞ}

Apendiks, eskiden karsinoid tümör olarak adlandırılan nöroendokrin tümörlerin (NET) en s1k (\%38) görüldüğü yerlerden biridir $(1,2)$. Çoğunlukla semptomsuz olup apendektomi veya diğer abdominal ameliyatlar sonrasında insidental olarak saptanır. Diğer organlardan ileumda $\% 23$, rektumda $\% 13$ ve bronşlarda $\%$ 11,5 sıklıkta görülür (3). Bu çalışmada akut apandisit ön tanısı ile apendektomi uygulanan hastaların patoloji sonuçları incelenerek NET saptanan hastalar değerlendirildi. Sonuçlar literatür ile karşılaştırıldı.

\section{MATERYAL VE METOT}

Ocak 2015 - Aralık 2016 tarihleri arasında Recep Tayyip Erdoğan Üniversitesi Eğitim Araştırma Hastanesi aciline başvuran ve akut apandisit ön tanısı ile opere edilen 586 hastanın dosyası ve apendektomi piyeslerine ait sonuçlar retrospektif olarak incelendi. Hastaların yaş, cinsiyet, histopatolojik tan1 ve patoloji sonucu apendiks NET olarak rapor edilen olguların makroskopik tümöral bulgu durumu, tümör yeri, tümör boyutu, cerrahi sınır, Ki 67 indeksi, mitotik indeks ve sonraki tedavileri değerlendirildi.

\section{Bulgular}

Hastaların 365' i erkek 228' i kadın olup yaş ortalamas1 28.2 (1- 88) idi. Histopatojik incelemeler değerlendirildiğinde üç hastada (\% $0.5)$ iyi diferansiye nöroendokrin tümör mevcut idi (Tablo 1). Bu üç hastaya ait spesmenlerde akut apandisit tespit edilmedi. Hastaların yaşları 15,35 ve 48 idi. Ameliyat esnasında tümöral bulgu gözlenmedi. Tümör boyutları sirasiyla $0.4,0.6$ ve $1.2 \mathrm{~cm}$ idi. Tüm olgularda tümör distal yerleşimli idi. Cerrahi sınır iki hastada negatif birinde pozitif idi. Her üç hastada Ki 67 proliferasyon indeksi $\% 2^{\prime}$ den az ve mitotik indeks $<2 / 10 \mathrm{Hpf}$ idi. Cerrahi sınır pozitif olan hastaya ameliyat sonras1 1 . ay sağ hemikolektomi yapıldı. Diğer iki hasta takip önerilerek taburcu edildi.

\section{TARTIŞMA}

Apendektomi yapılan hastalarda \%0.3-3 oranında primer apendiks tumorü saptanır.
Bunlardan en s1k görüleni NET (\% 32-57) olup ilk olarak 1867 ' de tanımlanmıştır. Diğerleri: goblet hucreli karsinom, lenfoma, mukosel, primer adenokarsinom ve musinoz kist adenokarsinomdur $\quad(2,4,5) . \quad$ NET ler endodermde yer alan enterokromafin veya Kulchitsky hücrelerinden gelişirler ve nöroendokrin hücrelerin olduğu tüm organlarda yerleşim gösterebilirler. Nöroendokrin sistemin. $\mathrm{Bu}$ hücreler özefagus haric gastrointestinal sistem, ürogenital sistem ve bronş epitelinde bulunur $(5,6)$. Apendektomi yapilan hastalarda NET saptanma oran1 \% 0.3$0.9^{\prime}$ dur (7). Siklıkla 30-40 yaşları arasında insidental olarak apendektomi veya diğer abdominal cerrahi işlemler sonrasında konulur. Çocuklarda da görülebilmektedir. Kadınlarda erkeklere oranla biraz daha fazla görülür. Genellikle ameliyat esnasında NET' den şüphelenilecek makroskopik bulgu gözlenmez (5). Ülkemizden iki ayrı çalışmada toplamda 4840 apendektomili hastada 16 apendiks NET (\% 0.3$)$ tespit edilmiştir $(3,5)$. Çalışmamızda insidental olarak 3 hastada $(\% 0.5)$ apendiks NET saptanmış olup literatür ile uyumlu bulunmuştur.

Klinik bulgular yönünden akut apandisitten ayırt etmek güçtür. Karın ağrısı en sık semptom olup ishal ve kilo kaybı eşlik edebilir. (8). Olgularımızın üçüde karın ağrısı, bulantı ve kusma şikayetleri ile acile başvuruda bulunmuşlardı. İnsidental saptanan apendiks NET' kerin prognozu iyidir. Vazoaktif aminlerin dolaşıma geçmesi sonucu yaklaşı \% 10 oranında karsinoid sendrom görülebilir. Karsinoid sendromda 5-hidroksitriptamin ve histamin artışına bağlı flushing, ishal, bronkokonstruksiyon ve periferik vazomotor semptomlar gözlenir. Metastaz oranını etkileyen faktörler tümörün çapı, lenf nodu varlığı, histolojik alt tipi (G1-3), cerrahi sınır, yüksek mitotik indeks, Ki 67 indeksi ve mezoapendiks-seroza yayılımıdır $(5,9,10)$. Mitotik indeks genellikle \% 1 altındadır. Eğer 10 büyük büyütmede $\%$ 2-3 bulunursa prognoz kötüdür. İmmünhistokimyasal çalışmalar kromogranin, sinaptofizin, Ki-67 proliferasyon indeksi, CAM5.2, CDX2, CD56 olup bunlardan tek birinin pozitif olması dahi NET tanısı için yeterli olmaktadır. Ki-67 prognozu, lokal veya uzak metastaz gelişimini tahmin etmeye yardımcı olan tümör içerisinde prolifere hücreleri gösterebilen bir antikordur (6). Ki-67 
yüksek olan tümörler, daha agresif seyretme eğilimindedir ve bu vakalarda vasküler invazyona, kötü proliferasyona ve metastaza daha sık rastlanır. Ki-67 \% 2'nin altında olması iyi prognoz kriteridir (9). Metastaz ve rekürrens prediktörleri olan Ki-67 ve mitotik indeksi temel alan WHO 2010 siniflaması karsinoid teriminin sadece karsinoid sendromda kullanılması gerektiğini önerir ve NET' leri Grade 1-2, nöroendokrin karsinomu ise Grade 3 olarak siniflar. $\mathrm{Bu}$ siniflamada G1 (iyi diferansiye-düşük evre): Ki-67<3\%, mitotik indeks <2/10 Hpf; G2 (Orta diferansiye, ara evre): Ki-67 3-20 \%, mitotik indeks 2-20/Hpf ve G3 (zayıf diferansiye-yüksek evre): Ki-67 $>20 \%$, mitotik indeks $>20 / \mathrm{Hpf}$ şeklindedir. (11)

NET' lerin \% 70'i 1 cm'den küçüktür (4) ve \%71'i apendiksin ucunda yerleşir. Tümör boyutu $1 \mathrm{~cm}$ altında iken metastaz olasılığ hic yokken; $2 \mathrm{~cm}$ üzeri tümörlerde metastaz sıklığ 1 $\%$ 20' ye kadar çıkmaktadır (4). Histopatolojik inceleme şarttır. Kolorektal malignite gelişme olasılığ1 unutulmamalıdır. Tümör boyutu $2 \mathrm{~cm}$ ' den büyük olgularda sağ hemikolektomi önerilmektedir. $2 \mathrm{~cm}$ altında ancak apendiks köküne lokalize tümör; lenfatik, serozal, mezoapendiks invazyonu; bölgesel lenf nodu metastazi; musin üretimi (goblet hücrelimusinöz karsinoid tümör) ve yüksek mitotik indeks ile birlikte hücresel pleomorfizm varlığında ve sağ hemikolektomiyi öneren çalışmalar vardır (1). Tumor $1 \mathrm{~cm}$ ' den küçük olduğunda ise sadece apendektomi yeterlidir $(1,3,5)$.

Apendiks NET' leri nadiren metastaz yapar $(4,12,13)$. Metastaz genellikle bölgesel lenf nodlarına ve tümör $2 \mathrm{~cm}$ ' e ulaştıktan ve mezoapendiks tutulduktan sonra olur. Çap 12 cm'den küçük tümörlerin minimal metastatik davranıştan dolayı başarıyla izlenebileceğini; serozal ve intramural lenfatik invazyonu olan tümörlerde apendektomi ve mezoapendiks rezeksiyonunun yeterli olacağını belirten çalışmalar mevcuttur $(9,13,14)$. Ayrıca vasküler, nöral veya lenfatik invazyon varlığı ikincil cerrahi işlem için kesin kriter olmayıp yakın takip gerektirir ve yeni bir cerrahi işlem hasta ile tartışılabilir (15). Bunun yanı sıra iyi diferansiye $2 \mathrm{~cm}$ 'den küçük tümörler eğer serozayı aşmış, mezoapendikse $3 \mathrm{~mm}$ ' den daha fazla invaze ve apendiks tabanına lokalize ise daha fazla rezeksiyon gerekebilir $(15,16)$.
NCCN 2017 k1lavuzuna göre $2 \mathrm{~cm}$ altında ve apendikse lokalize tümörlerde apendektomi yeterlidir. $2 \mathrm{~cm}$ altında olup eşlik eden lenfovasküler veya mezoapendiks invazyonu veya atipik histolojik özellikler varlığında daha agresif tedavi düşünülebilir. Cerrahi sınır pozifliği veya $2 \mathrm{~cm}$ üzeri tümör varlığ durumunda ise abdominopelvik BT veya MR eşliğinde evreleme yapılması, uzak metastaz saptanmaması halinde reekplorasyon ile sağ hemikolektomi önerilir (17). Goede ve ark. 1-2 cm arası tümörlerin tartışmalı olduğunu mezoda yayılım, pozitif cerrahi sinırlı bazal yerleşimli apendiks tümörü varlığı, cekuma yayılım, yüksek mitotik indeks ve Ki-67 artış1 durumlarında ise sağ hemikolektomi uygulanabileceğini belirtmiştir (9). Çalışmamızda saptanan tümör çapları $2 \mathrm{~cm}$ 'den küçük idi ancak bir hastada cerrahi sınır pozitif idi. $\mathrm{Bu}$ hastaya reekplorasyon ile sağ hemikolektomi uygulandı. Çalışmamızda iki hastanın tümörü $1 \mathrm{~cm}$ den küçük, bir hastanın ise büyük olup tümü distal uç yerleşimli idi.

Metastatik veya karsinoid sendrom gelişen olgularda, sitoreduktif kemoterapi ve tümörün ürettiği bioaktif maddelerin medikal kontrolü önerilir. Streptozosin ve 5-florourasil veya doksorubisinle kombine kemoterapi ile tedaviye cevap \% 40 altındadır. Somatostatin analoğu octreotid, en etkili farmakolojik ajandır. Rezeke edilemeyen diffuz karaciğer metastazlı olgularda radyoterapi, radyofrekans ablasyon, kriyoablasyon ve hepatik arter kemoembolizasyonu da tedavi seçenekleri arasindadir $(5,18)$.

Sandor ve ark.nın 1973 and 1991 arasında Ulusan Amerikan Kanser Enstitüsünde tedavi ettikleri 1570 apendiks karsinoid tümörlü hastada yaptıkları çalışmada lokalize, bölgesel ve uzak metastazı olan hastalarda 5 yıllık sağ kalım sirasiyla \% 94, 84.6 ve 33.7; ortalama sağ kalım ise \% 85 olarak bulunmuştur (19). Modlin ve ark.nın 13715 karsinoid tümörlü hastayı kapsayan geniş kohortunda ise 5 yıllık sağ kalım lokal hastalıkta \% 92, bölgesel metastaz varlığında \% 81, uzak metastazda ise $\% 31$ olarak tespit edilmiştir (6).

NCCN 2017 k1lavuzunda $2 \mathrm{~cm}$ alt tümörlerin takibinde kesin kriterler belirtilmemiştir. $2 \mathrm{~cm}$ üzerindeki tümörlerde ise ilk y1l her 3 ayda bir, sonraki 10 yıl için ise her 6-12 ayda bir hikâye, FM ve görüntüleme ile 5HIAA ve Kromogranin A ölçümü önerilmektedir (17). Hasta takiplerinde senkron 
veya metakron kolorektal tümör gelişme riskinin \%30 un üzerinde olduğu unutulmamalıdır $(9,12,20)$.

\section{SONUÇ}

Apendiks NET' leri sıklikla apendektomi piyeslerinde insidental olarak tespit edilir. Histopatoloji öncesinde tanı koymak oldukca zordur. $1 \mathrm{~cm}$ altında ki tümörlerde apendektomi yeterli olup, $2 \mathrm{~cm}$ üzerinde sağ hemikolektomi planlanmalıdır. 1-2 cm aras1 tümörlerde ise mutlaka patoloji sonucundaki özellikler dikkate alınarak ayrıntılı değerlendirme yapılmalıdır. Genel sağ kalım iyi olmakla birlikte kolorektal malignite gelişme olasılığı unutulmamalıdır.

\section{Çıkar çatışması: Yok}

\section{REFERANSLAR}

1. Ma KW, Chia NH, Yeung HW, Cheung MT. If not appendicitis, then what else can it be? A retrospective review of 1492 appendectomies. Hong Kong Med J 2010; 16(1): 12- 17.

2. Meşină C, Vasile I, Vilcea ID, Paşalega M, Calotă F, Enache DS, et al. Carcinoid tumour of the appendix: problems of diagnosis and treatment. Chirurgia (Bucur) 2011; 106(2): 239-245.

3. Eğin $S$, Hot S, Yeşiltaș M, Kamalı S, Gökçek B, Yllmaz E ve ark. Apendiks'in Karsinoid tümörü: 3769 Ardışık Acil Apendektomi. Okmeydanı Tıp Dergisi 2014; 30(3):135-138.

4. Tchana-Sato V, Detry O, Polus M, Thiry A, Detroz B, Maweja S, et al. Carcinoid tumor of the appendix: a consecutive series from 1237 appendectomies. World J Gastroenterol 2006; 12(41): 6699-6701.

5. Başak F, Hasbahçeci M, Canbak T, Acar A, Baş G, Alimoğlu O. İnsidental Saptanan Apendiks Karsinoid Tümörü. J Kartal TR 2014; 25(1): 19-22.

6. Modlin IM, Lye KD, Kidd M. A 5-decade analysis of 13,715 carcinoid tumors. Cancer 2003; 97(4):934959.

7. In't Hof KH, van der Wal HC, Kazemier G, Lange JF. Carcinoid tumour of the appendix: an analysis of 1,485 consecutive emergency appendectomies. J Gastrointest Surg 2008; 12(8):1436-8.

8. Spallitta SI, Termine G, Stella M, Calistro V, Marozzi P. Carcinoid of the appendix. A case report. [Article in Italian] Minerva Chir 2000;55(1-2):7787.
9. Goede AC, Caplin ME, Winslet MC. Carcinoid tumour of the appendix. $\mathrm{Br} \mathrm{J}$ Surg 2003;90(11):1317-1322.

10. Coşkun H, Bostanci O, Dilege ME, Mihmanli M, Yilmaz B, Akgun I, et al. Carcinoid tumors of appendix: treatment and outcome. Ulus Travma Acil Cerrahi Derg 2006;12(2):150-154.

11. Oberg K, Castellano D. Current knowledge on diagnosis and staging of neuroendocrine tumors. Cancer Metastasis Rev 2011;30(suppl 1):3-7.

12. Moertel CG, Weiland LH, Nagorney DM, Dockerty MB. Carcinoid tumors of the appendix: treatment and prognosis. N Engl J Med 1987;317(27):16991701.

13. Butler JA, Houshiar A, Lin F, Wilson SE. Goblet cell carcinoid of the appendix. Am J Surg 1994;168:685687.

14. Toumpanakis C, Standish RA, Baishnab E, Winslet MC, Caplin ME. Goblet cell carcinoid tumors (ade $\neg$ nocarcinoid) of the appendix. Dis Colon Rectum 2007;50(3):315-322.

15. John K Ramage, A Ahmed, J Ardill, et al. Guidelines for the management of gastroenteropancreatic neuro $\neg$ endocrine (including carcinoid) tumours (NETs). Gut 2012; 61:6-32.

16. Plockinger U, Couvelard A, Falconi $M$, et al. Consen $\neg$ sus guidelines for the management of patients with digestive neuroendocrine tumours: well-differentiated tumour/carcinoma of the appendix and goblet cell car cinoma. Neuroendocrinology 2008; 87:20-30.

17. National Comprehensive Cancer Network. NCCN clinical practice guidelines in oncology: neuroendocrine tumors. https://www.nccn.org/professionals/physician_gls/p df/neuroendocrine.pdf. Accessed June 27, 2017.

18. Chapman WC, Debelak JP, Wright PC, Washington MK, Atkinson JB, Venkatakrishnan A, et al. Hepatic cryoablation, but not radiofrequency ablation, results in lung inflammation. Ann Surg. 2000;231 (5):752-761.

19. Sandor A, Modlin IM. A retrospective analysis of 1570 appendiceal carcinoids. Am J Gastroenterol 1998;93:422-428.

20. Connor SJ, Hanna GB, Frizelle FA. Appendiceal tumors: retrospective clinicopathologic analysis of appendicealtumors from 7,970 appendectomies. Dis Colon Rectum 1998;41(1):75-80. 